\title{
Making sense of 'teaching', 'support' and 'differentiation': the educational experiences of pupils with Education, Health and Care Plans and Statements in mainstream secondary schools
}

Article

Accepted Version

Webster, R. ORCID: https://orcid.org/0000-0003-1416-4439 and Blatchford, P. (2019) Making sense of 'teaching', 'support' and 'differentiation': the educational experiences of pupils with Education, Health and Care Plans and Statements in mainstream secondary schools. European Journal of Special Needs Education, 34 (1). pp. 98-113. ISSN 0885-6257 doi: https://doi.org/10.1080/08856257.2018.1458474 Available at https://centaur.reading.ac.uk/92016/

It is advisable to refer to the publisher's version if you intend to cite from the work. See Guidance on citing.

To link to this article DOI: http://dx.doi.org/10.1080/08856257.2018.1458474

Publisher: Taylor \& Francis

All outputs in CentAUR are protected by Intellectual Property Rights law, including copyright law. Copyright and IPR is retained by the creators or other copyright holders. Terms and conditions for use of this material are defined in 
the End User Agreement.

www.reading.ac.uk/centaur

\section{CentAUR}

Central Archive at the University of Reading

Reading's research outputs online 


\title{
Making sense of 'teaching', 'support' and 'differentiation': the educational experiences of pupils with Education, Health and Care Plans and Statements in mainstream secondary schools
}

Rob Webster* and Peter Blatchford, UCL Institute of Education

\begin{abstract}
This paper reports on results from a descriptive study of the nature and quality of the day-today educational experiences of 49 13-14 year-olds with special education needs and/or disabilities (SEND). All pupils had either an Education Health and Care Plan (EHCP) or a Statement, and attended in mainstream secondary school in England. Pupils involved in the SEN in Secondary Education study were shadowed for several days over a school week. Researchers prepared pupil-level case studies on the basis of data from qualitative observations and semi-structured interviews with pupils and key school staff involved in their learning and development. The case studies were subjected to a thematic analysis. Results are presented in terms of two inter-related themes - (i) teaching and support; and (ii) differentiation - which address approaches to, and expressions of, inclusive practice; the roles of teachers and teaching assistants; and the defining features of teaching and support for SEND. The results are considered in view of the inclusiveness, appropriateness and effectiveness of provision on offer to pupils with high-level SEND. We conclude there has been a systemic and long-standing failure to fully address the educational needs of such pupils, and suggest what schools could do to provide higher quality experiences.
\end{abstract}

Key words: inclusion; differentiation; pupil voice; teaching assistants

\section{Background}

Around 1.2 million pupils in England have special educational needs and disabilities (SEND) (DfE, 2017a). Around a quarter of these have needs entitling them to an Education, Health and Care Plan (EHCP): a legal document setting out a pupils' needs and the support they should receive. Prior to 2014, another legal document called a Statement performed the same function. The proportion of pupils with a Statement or EHCP ${ }^{1}$ has remained stable at $2.8 \%$ since 2010 . Slightly more of these pupils (45\%) are educated in state-funded mainstream schools than in state-funded special schools (43\%) (DfE, 2017a).

Concurrent with the long-term, international trend towards inclusion, the increase in the number of pupils with SEND educated in mainstream UK schools over the last 30 years has been accompanied and assisted by an increase in the number of support paraprofessionals, known variously as teaching assistants, learning support assistants or classroom assistants (referred to here as TAs). The number of full-time equivalent TAs in mainstream schools in

\footnotetext{
${ }^{*}$ Corresponding author. Department of Psychology and Human Development, UCL Institute of Education, London, WC1H 0AL, UK. Email: rob.webster@ucl.ac.uk
} 
England has more than trebled since 2000, from 79,000 to 265,600 in 2016. TAs comprise $28 \%$ of the school workforce in England (DfE, 2017b).

SEND provision in mainstream settings in other OECD countries, also relies heavily on paraprofessionals (Masdeu Navarro, 2015). In England, the national annual spend on TAs is around $£ 5$ bn (Webster et al., 2016). On the face of it, this seems a worthwhile investment. School leaders report that a main reason for the increase in TAs is that inclusion policies would be impossible to implement without them (Blatchford et al., 2012). However, results from the longitudinal Deployment and Impact of Support Staff (DISS) project raised serious questions about the negative consequences of how deploying TAs in a predominantly pedagogical role has become closely connected to policies and practices of inclusion (Webster et al., 2010).

On the basis of extensive data collected via observations, surveys, interviews and audio recordings of lessons, the main explanation for the DISS project results on attainment appeared to be the way TA-supported pupils spend less time interacting with the teacher, and become separated from the teacher and curriculum. As the least qualified staff (TAs) are, in effect, assigned primary educator status for the pupils in most need, it is perhaps unsurprising that these pupils make less progress than their peers. Similarly, Klassen (2001) found pupils with dyslexia, who were assigned TA support for literacy, made less progress than their unsupported peers. There are, however, very few studies describing the day-to-day experiences of pupils with high-level SEND (i.e. those with Statements/EHCPs) of life and learning in mainstream settings, which may help explain why this common approach to facilitating inclusion - the employment and deployment of TAs - lacks impact.

One exception is the Making a Statement (MAST) study, which tracked the educational experiences of 48 nine- and ten-year-olds with Statements (Webster and Blatchford, 2013; 2015). The findings, based on interview and observation data, revealed how the everyday experiences of pupils with Statements were markedly and qualitatively different to pupils without SEND. Organisational reliance on TAs to facilitate inclusion meant that school life for pupils with high-level SEND was strongly characterised by a high degree of separation from the classroom, their teacher and peers. The particular power invested in the Statement, and the characterisation of support being couched in terms of 'TA hours', calls to mind what Sikes et al. (2007) refer to as the 'yes buts' of inclusion; where the inclusion of pupils with SEND is conceived as being contingent on available resources.

As was found in the DISS project (Blatchford, et al., 2011), a main conclusion from the MAST study was that pupils with Statements received a different - and less effective - pedagogical diet compared to pupils without SEND. TAs assumed much of the responsibility for momentby-moment pedagogical decision-making for these pupils. They provided a high amount of verbal differentiation, in part to make classroom teaching accessible, but also to compensate for the teachers' failure to set appropriate tasks. While TAs' interactions with pupils were well-intentioned, their nature and appropriateness were qualitatively different to teacher-topupil talk. More detailed studies of adult-pupil interactions have found that TAs tend to close talk down, rather than open it up, as teachers do (Radford et al., 2011). Elsewhere, analyses by Rubie-Davies et al. (2010) found that compared to teachers, TAs are more concerned with task completion and correction than learning. The limited research on, and involving, pupils with high-level SEND in secondary schools means little is known about the precise role of TAs 
and the nature of their support (e.g. via their talk), and how this converges and differs from the role of teachers and teaching for these pupils.

Allied to this is differentiation, which we know from the MAST study is under-conceptualised (Webster and Blatchford, 2015). Prominent in primary school teachers' conceptualisations and operationalisations of differentiation were the use of within-class (so-called) 'ability' grouping and the positioning of a TA next to a pupil with high-level SEND ('one-to-one support'). Further differentiation was provided by TAs' moment-by-moment interactions. Other commonly occurring expressions of differentiation were: (i) by task; and (ii) by outcome (i.e. the amount of work completed or produced). While the MAST study shone light on the unstructured ways in which differentiation is, to a fair degree, operationalised by TAs filling the gaps left by teachers, what is less known is what is understood by differentiation and how it is operationalised in secondary settings.

\section{This paper}

This paper reports on results from a qualitative study of pupils with Statements/EHCPs educated in mainstream secondary schools. On concluding the MAST study (conducted in primary schools during 2011/12), we identified an exciting opportunity to do a replication study in secondary schools. The main aim of the SEN in Secondary Education (SENSE) study was to provide descriptive information about the day-to-day experiences of secondary-aged pupils with high-level SEND via a mixed-methods approach.

The approach adopted in the SENSE study was similar to the MAST study. Researchers shadowed pupils for between three and five days over a school week. The multi-method approach to data collection combined systematic observations and a complementary analysis of qualitative case study data. This paper reports on results from the second of these components.

The systematic observation results found that pupils with Statements/EHCPs were largely taught in small homogenous, low-attaining classes. We concluded that this was very close to a form of streaming (Webster and Blatchford, 2017). TAs were a consistent feature of these classrooms, and especially so in the lives of pupils with Statements/EHCPs. Interactions with TAs accounted for around one-fifth of all their interactions, and outweighed peer interactions. In contrast, TAs were less common in classes for average-attaining (non-SEND) pupils. Consequently, only $1 \%$ of all interactions they experienced were with TAs.

Whilst these findings provide robust data on the broad contextual features of secondary school life for pupils with and without SEND, we know little of detail of what occurs within classrooms, and how it is experienced and perceived by various stakeholders. A key purpose of the qualitative case studies, therefore, was to capture and synthesise data on conceptualisations of, and approaches to, teaching and support and differentiation among school staff, and the views of the young people with Statements/EHCPs who experience this. As we describe in the methodology below, the basis for the SENSE study case studies were semi-structured interviews with school staff and pupils, which covered: approaches to including pupils with high-level SEND; curriculum access; the roles of teachers and TAs; and the defining features of teaching and support (including adult-pupil interaction). 
The rationale for this investigation is that there is a need for more empirical research on under-theorised practices in secondary education that tend to be presented as appropriate provision and pedagogy for pupils with high-level SEND. There remains a paucity of quality evidence, especially in the UK, about pedagogic practice for pupils with SEND in mainstream settings. A systematic literature review by Rix et al. (2009) on this topic yielded 28 papers for in-depth analysis; just 1\% of the total they started with. Only ten of these scored well in terms of research design.

A main aim of this paper is to establish what secondary school practitioners and pupils understand by the potentially nebulous and contestable terms 'teaching', 'support' and 'differentiation', pertaining to SEND. As our study was interested in how pupils experience these things in practice, this paper makes a useful contribution to the literature by giving a voice to young people with learning difficulties; a constituency at risk of marginalisation (Nye, 2017). In the concluding section, we contextualise our findings in relation to the wider evidence base, and consider the implications in light of trends and projections concerning SEND provision and inclusion in England.

Through this paper, we hope to inform wider debates about what constitutes effective inclusive provision for pupils with high-level SEND. In the UK at least, the persistent failure to meet the educational needs of pupils with SEND appropriately and proportionately has raised significant concerns about fairness and discrimination. In addition, school failure (i.e. leaving compulsory education without qualifications, or having inadequate literacy and numeracy skills) has long-term damaging effects for society, as well as for the life-chances of the individuals concerned (O'Brien, 2016). Insights that contribute to the development of meaningful inclusive learning experiences have the potential to inform improved life journeys for pupils with SEND.

\section{Methodology}

\section{Sample}

Pupils

Working with local authority ${ }^{2}$ colleagues, the research team identified 13-14 year-olds (Year 9s) in mainstream secondary schools, with a Statement/EHCP. In the main, it was the strategic lead for SEND, the SEN coordinator (SENCO), who then facilitated the process of securing informed consent from the pupils and their parents/carers. School visits were carried out between autumn 2015 and spring 2016. For the purposes of consistency with the earlier MAST study, we prioritised pupils with difficulties relating to cognition and learning for inclusion in the SENSE study33. Pupils with a Statement/EHCP relating to the categories of need prevalent within cognition and learning - moderate learning difficulties and severe learning difficulties - together account for $16 \%$ of all pupils with Statements/EHCPs in mainstream secondary schools. Table 1 shows the pupil sample by key characteristics.

Table 1. Pupils with Statements/EHCPs

\begin{tabular}{|c|c|c|c|c|c|c|c|}
\hline & \multicolumn{2}{|c|}{ Gender } & \multicolumn{2}{c|}{ Ethnicity } & \multirow{2}{*}{ EAL } & \multirow{2}{*}{ FSM } & $\begin{array}{c}\text { Total } \\
\text { pupils }\end{array}$ \\
\cline { 2 - 5 } & Boy & Girl & White & Other & & & \\
\hline
\end{tabular}




\begin{tabular}{|l|c|c|c|c|c|c|c|c|c|c|c|c|c|c|}
\hline $\begin{array}{l}\text { Cognition and } \\
\text { learning }\end{array}$ & 28 & $82 \%$ & 12 & $80 \%$ & 32 & $80 \%$ & 8 & $89 \%$ & 5 & $83 \%$ & 12 & $80 \%$ & 40 & $82 \%$ \\
\hline $\begin{array}{l}\text { Other } \\
\text { primary } \\
\text { need }\end{array}$ & 6 & $18 \%$ & 3 & $20 \%$ & 8 & $21 \%$ & 1 & $11 \%$ & 1 & $17 \%$ & 3 & $20 \%$ & 9 & $18 \%$ \\
\hline Total & 34 & $69 \%$ & 15 & $31 \%$ & 40 & $82 \%$ & 9 & $18 \%$ & 6 & $12 \%$ & 15 & $31 \%$ & 49 & $100 \%$ \\
\hline
\end{tabular}

* Communication and interaction difficulties (4 pupils); social, emotional and mental health difficulties (3 pupils); and sensory and/or physical needs (2 pupils).

In terms of representativeness, at January 2016 (during the fieldwork phase), there were 50,884 pupils attending state-funded secondary schools with Statements/EHCPs (DfE, 2016c). Just under a fifth were in Year 9. Of these, 75\% were boys and 75\% were white British; 25\% identified as being in another ethnic group. Our sample diverged marginally from these proportions. Pupils with Statements/EHCPs known to be eligible for free school meals (FSM) were slightly over-represented in our sample (26\% nationally), whilst pupils whose had English as an additional language (EAL) were in line with the national picture (11\% nationally). Most pupils (78\%) in our sample had a specific number of TA support hours expressed on their Statement/EHCP. Three-quarters (74\%) had 20 or fewer hours, and only a few pupils had 'full time' TA support (e.g. around 30 hours).

\section{Schools}

Researchers collected data in 34 schools across England. In line with the national picture (Ofsted, 2016), three-quarters of schools were rated either good or outstanding at their last inspection. All of the schools were non-selective state schools for 11- to 16-year-olds. Pupil rolls ranged from 317 to 2,187, with most schools having between 1,000 and 1,299 pupils; slightly above the national average of 939 pupils (DfE, 2016d). The average proportion of pupils in English secondary schools with a Statement/EHCP is 1.7\% (DfE, 2016e). Just over half the schools in the SENSE study sample exceeded this. Eight schools had an additional resource provision for pupils with SEND. Most schools (71\%) were located in predominantly urban areas.

\section{Methods of data collection}

Completion of the fieldwork was achieved in partnership with five providers of the Doctorate in Educational Psychology programme; the post-graduate professional training course for educational psychologists in England. Trainees received a full day of training in the data collection approach, methods and tools. As mentioned, we used the same methods and analytical approach deployed in the MAST study (Webster and Blatchford, 2015). Each researcher produced a detailed case study report on an individual pupil with a Statement/EHCP. Case studies drew together data from several sources, described below.

Semi-structured interviews with pupils and school staff focussed on the experiences, perceptions and expectations of stakeholders. The questions flowed from a set of predetermined headings. The same questions were put to all school staff. Interviews were conducted once the researcher was acquainted with the situation in school, and so able to 
nuance questions to reflect their observations. Interviews lasted between 20 minutes and an hour. A total of 219 interviews (see Table 2) were conducted and used as basis for the construction of the case study reports.

Researchers had access to documentary evidence for the pupil they shadowed, including their Statement/EHCP and annual reviews. These documents detailed their current educational needs (and, where relevant, health, care and other needs), together with the provisions that should have been in place to meet those needs. The allocation of TA support hours (where given) was also recorded on these documents. Finally, researchers kept on-going, open-ended field notes of qualitative observations, contextual details, thoughts and impressions on the pupil experience being observed. These notes supplemented and assisted the interpretation of data from other sources.

Table 2. Interviewees

\begin{tabular}{|r|c|c|}
\hline Pupil with Statement/EHCP & 44 & $20 \%$ \\
\hline Teaching assistant & 54 & $25 \%$ \\
\hline Teacher & 56 & $26 \%$ \\
\hline SENCO & 57 & $26 \%$ \\
\hline Other school staff & 8 & $4 \%$ \\
\hline Total & 219 & $100 \%$ \\
\hline
\end{tabular}

Note. percentages have been rounded-off

\section{Case study reports}

An often-cited challenge of working with qualitative data is that they are 'strong in reality', but difficult to organise (Cohen and Manion, 1994). To organise the considerable volume of qualitative data, researchers drew together material from the sources above into a pupil-level case study report. A total of 49 reports were compiled, each providing a substantive picture of their educational experiences to complement and expand that captured by the systematic observations. Report data were organised thematically according to the framework used to construct the MAST study case study reports (Webster and Blatchford, 2015), using themes relatable to secondary schools.

Citing Becker (1958), Walker (1993) writes that case study researchers frequently gravitate toward quantitative analyses of qualitative data in order to establish the main foci of research, by identifying the typicality and frequency of particular events, and how they are distributed among categories of people and organisational units. For the purposes of efficient interrogation, we arranged the data from the case study reports using the predetermined headings. Then, using a subsample of 13 reports, we conducted an open-ended inductive analysis, allowing points of interest to emerge. The situations, incidences, issues, experiences and views that featured across several case studies were then used to construct detailed coding frameworks for each heading. This allowed us to make plausible and credible generalisations, whilst retaining the individuality of particular cases to serve as illustrative examples of specific points. The prevalence of key and recurring features contained in the 
data were coded. The data analysis process validated our predetermined headings, and these then provided a set of emergent overarching themes capturing the main findings from the case studies.

In this paper, we report on the case study data collated under selected themes, which covered: approaches to, and expressions of, inclusive practice; curriculum access; the roles of teachers and TAs; and the defining features of teaching and support, as they related to pupils with Statements/EHCPs. For the purposes of reporting, these data have been collapsed under two broad headings: (i) teaching and support; and (ii) differentiation.

In the presentation of results that follows, we provide an indication of prevalence of findings, by stating the number of case studies in which a specific issue, characteristic, experience or viewpoint was identified as $n=x$, where $x$ equals the number of cases out of a maximum of 49 . A prevalence was only counted when it was unequivocally evident in a case study report.

\section{Results}

\section{Theme 1. Teaching and support}

Here, we cover the data relating to the role of teachers and TAs, the teaching and support they provide, and the features of the interactions each have with pupils with Statements/EHCPs. What emerged strongly in almost every case study report was the extent to which TAs were a central feature in the lives of pupils with high-level SEND. Statements/EHCPs were viewed as essential for securing the funding for TA support, which in turn, ensured and facilitated the pupils' inclusion in a mainstream setting.

Though many schools reported they did not allocate a specific TA to individual pupils with Statements/EHCPs $(n=21)$, in practice, there was a high reliance on, and use of, one-to-one TA support. Indeed, in 22 cases, the pupil was allocated a one-to-one TA. A few interviewees commented on the rationale for one-to-one support in terms of maintaining classroom order.

"Some teachers do like someone to be sat with him all the time... mainly to do with behaviour rather than attainment".

SENCO

In the main, the impact of high levels of TA support was described positively, and was viewed in almost all cases as essential for successful inclusion.

"Without support he can't survive in school".

TA

"Without TA support, [pupil] would be "tragically unhappy". He is now very happy and settled".

SENCO

However, high levels of one-to-one TA support, particularly where it was unsolicited, could have a stigmatising effect on pupils $(n=10)$. 
"Sometimes I just like working on my own. So, like, in lessons where I'm not in the bottom group and I have a helper there, it just lowers my confidence. Because I don't like feeling that I need help and that everyone else thinks I need help, when I don't. It's just sort of embarrassing".

Pupil

"Sometimes when I don't need them [TAs], I'm like: 'go away. I don't need the help"'. Pupil

References to 'support' required further elucidation, so TAs and teachers were asked to describe the nature of their role and interactions in relation to pupils with Statements/EHCPs. The key features of the teachers' role included: prompting, reminding, encouraging and praising $(n=14)$; promoting independence $(n=14)$; questioning $(n=11)$; clarifying and repeating information $(\mathrm{n}=11)$; helping pupils to start work $(\mathrm{n}=10)$; teaching new concepts $(\mathrm{n}=6)$; reinforcing concepts $(\mathrm{n}=5)$; deepening understanding $(\mathrm{n}=5)$; modelling $(\mathrm{n}=5)$; and helping pupils stay on task/focussed $(n=4)$. Much beyond this, teachers seemed unable to pinpoint ways in which they provided additional or differentiated teaching. Overall, the impression about pedagogical approaches gained from the case studies was one of ambiguity and vagueness.

The features of the TAs' role and input overlapped with that of teachers. TAs were: clarifying and repeating information $(\mathrm{n}=22)$; keeping pupils on task/focussed $(\mathrm{n}=21)$; promoting independence $(n=20)$; prompting, reminding, encouraging and praising $(n=17)$; helping them to start work $(n=14)$; reinforcing concepts and information $(n=11)$; questioning $(n=11)$; and deepening understanding $(\mathrm{n}=10)$.

As with teachers, TAs did not find it easy to describe the 'support' and 'help' they said they provided. This extended to teachers' descriptions of the TA role. By and large, pupils with Statements/EHCPs described the support they received from TAs as always or often helpful, but they too were unable to articulate its key characteristics. A theme within the examples of what we might describe as 'more effective' expressions of TA support was how TAs left space for pupils to attempt tasks.

"If I have an assistant in maths, they will come to me in the first three questions and see I've done it like the first 30 seconds, so they just leave me to it and by the end of it I've got onto the extension work and maybe finished that".

Pupil

Some pupils reported that TAs provided too much help. This is at variance to the finding that many interviewees considered promoting independence to be key part of the TAs' role.

"It feels like cheating... if they are writing down everything for me".

Pupil

[Pupil] stated that she is aware that she writes really slowly, but that TAs make her feel rushed when they take over some of the writing at times. She stated that she dislikes this as it looks to the teacher as though she hadn't done her own work. [Pupil] does not feel comfortable telling the TA that she doesn't like this. 


\section{Excerpt from case study report}

To summarise, individual support from TAs emerges as critical to the inclusion of pupils with high-level SEND in mainstream secondary schools. While it was difficult to obtain a clear sense of the support TAs provided, insight gained from descriptions of their interactions with pupils revealed an overlap with teachers' teaching. Finally, there appears to be an unintended consequence of close proximity, high frequency TA support in terms of pupils' opportunities for, and sense of, independence.

\section{Theme 2. Differentiation}

The fuzziness relating to definitions of teaching and support extended to conceptualisations and operationalisations of differentiation. Below, we describe the main forms of differentiation described in the staff interviews.

\section{Differentiation by attainment grouping}

As described earlier, the results from the systematic observations showed that pupils with Statements/EHCPs were largely taught in small homogenous, low-attaining classes, with at least one TA present (plus the teacher). Their average-attaining peers, meanwhile, were taught in larger homogenous classes, with just the teacher present. Our conclusion that this was close to a form of 'streaming' is supported by evidence from the case studies. In half of all cases $(n=24)$, interviewees reported that smaller sized, 'streamed' classes were helpful for pupils with high-level SEND, as these were quieter and calmer learning environments.

"His class is a Foundation class [of 10 pupils]. It models the primary school format in that they are taught most core subjects together. For other subjects - PE, music and dramathey are integrated within the year group".

TA

Furthermore, in 28 out of 49 cases, SENCOs, teachers and TAs referred to the use of attainment grouping as a broad, structural approach to differentiation. In some cases, the allocation to lower-attaining sets was seen to obviate the need for differentiated tasks.

The SENCO recognised that many teachers within the school did not know how to differentiate effectively, which had an impact on pupils with SEN. He felt the provision was differentiated, as many classes [pupil] attended were streamed.

Excerpt from case study report

"I think the setting helps because [pupil] will be in lower bands. She's in lower groups, she doesn't actually need differentiation".

SENCO

While school staff viewed these organisational arrangements as part of a wider strategy for teaching and learning, some pupils felt there was a stigma attached to being in the 'bottom sets'. Low attainment classes were often referred to in interviews as 'low ability' groups; a freighted term, carrying implicit meanings about innate and fixed levels of aptitude. 
"I don't really like telling my friends that I'm in the bottom set, because I think they would find me different. I don't find it comfortable telling my friends".

Pupil

"It's alright, but I don't like being in a lower class. People start being rude, they say rude things, and I want to go to a higher one, so then I can do a proper test".

Pupil

\section{Differentiation by TAs}

Consistent with what was found in the MAST study, the most recurrent expression of practical differentiation was in terms of the allocation and presence of TAs $(n=29)$, and the support they provided via their interactions. TAs 'bridged' the learning in the moment through repetition and modifications to their language.

"Task simplification, re-explaining tasks, helping him to make sense of what has been asked of him; breaking tasks down and just getting [pupil] going by setting him off in some way".

TA

[TA] differentiates tasks within lessons for [pupil] ... by asking the pupil to write a smaller amount and scribing the rest for them to reduce writing demand, and "set them a target they can achieve".

Excerpt from case study report

It was difficult to get beyond these descriptions to uncover specific strategies and what drove TAs' decision-making in terms of how, when and why they are used in their moment-bymoment interactions with pupils. TAs tended to operate in the gaps left by teachers, and were trusted and empowered to differentiate in the moment.

"TAs are responsible and professional. They will differentiate, and read and scribe, and whatever [pupil] needs. Teachers often leave the differentiation for the children with Statements to the TA".

SENCO

While clearly well-intentioned, how successful and sustainable this is as an appropriate and long-term pedagogical strategy is questionable, as the following comments attest.

"In theory, it should be the class teacher's responsibility [to differentiate]. Often, we find it's the TA in practice who does that".

SENCO

[Pupil] mentioned he likes working with TAs as they 'tell him all the answers'.

Excerpt from case study report

Differentiation by task 
Teachers and TAs talked about differentiation at the task level in two ways. Firstly, for subgroups of lower-attaining pupils and those with SEND within the class $(n=13)$. In a few cases, pupils could choose their level of challenge from a small selection of tasks. Secondly, and more commonly, for individual tasks $(n=28)$, the pupil with a Statement/EHCP was given a specific, separate worksheet. These tasks tended to offer a lower level of challenge.

The Assistant SENCO, TA and the maths teacher all regarded differentiation for students with SEN as making the work easier. They gave no indication that differentiation may include, for example, presenting the material in a different way.

Excerpt from case study report

\section{Differentiation by outcome}

In just under a third of cases $(n=15)$, school staff referred to differentiation by outcome: the expectation that pupils with SEND would produce less work than their peers.

"[Teachers] will say, 'Will [pupil] manage this?', and I'll say: "No. Is it alright if we do the first five out of ten questions?"

TA

This, and some other comments we have used to illustrate the findings under this theme, reveal something about teachers' confidence and ability to set appropriate tasks for pupils with high-level SEND, as well as the reliance on TAs to facilitate learning (i.e. mediate teaching and curriculum access), despite not possessing the pedagogical training expected of teachers.

Differentiation by use of resources

Finally, visual aids and physical resources, such as large font sheets, were a commonly mentioned mode of differentiation $(n=23)$. In a quarter of cases $(n=13)$, ICT/assistive technology was cited. The comment below from a pupil reveals an interesting reflection on the use of supportive aids.

[Pupil] uses assistive technology for producing written work, but when I asked him about this, he said that it wouldn't help: "It's all about practise. If you have bad handwriting, a computer won't help. You just need to practise".

Excerpt from case study report

To summarise, what emerges strongly in the analysis of data under Theme 2 is how broadly differentiation was interpreted, but at the same time, how narrow and under-conceptualised some of definitions were. Differentiation operated at organisational levels (through setting) and interactional levels (via TA talk), and in some cases, this was viewed as sufficient. Given the ambiguity over how teaching and support were described (Theme 1), questions remain about what teachers. specifically, do to ensure classroom teaching and learning tasks are accessible to pupils with SEND.

\section{Discussion}


It is important to the interpretation of findings to not lose sight of the turbulent context in which our research was conducted. Pressures relating to funding, staffing, accountability and the implementation of numerous (and sometimes competing) policy initiatives, all have a bearing on SEND provision. Therefore, we should make clear that there was some evidence of good practice in a number of schools (Webster and Blatchford, 2017). We note too that the SENSE study is not without its limitations. We focussed mainly on pupils whose primary need related to cognition and learning, and so our findings cannot claim to represent the full range of complex, and sometimes co-occurring, needs for which Statements/EHCPs are written. Similarly, the study was limited only to pupils in the third of five years of compulsory secondary education. Nonetheless, the amount and depth of the qualitative data collected allow us to make some robust and valid conclusions. We now summarise the main findings and begin contextualising our conclusions with reference to the wider literature and the trends and trajectories regarding SEND policy, provision and practice in England.

Firstly, we found that individual support from TAs was a central factor in the inclusion and education of pupils with Statements/EHCPs. Despite a large-scale reform of the SEND system, it is difficult to avoid the conclusion that - much as we found in primary schools (Webster and Blatchford, 2015) - secondary schools view the employment and deployment of TAs as a key strategic approach to including and meeting the educational needs of pupils with high-level SEND. Underlying this is the way the currency of support, expressed in terms of TA hours, is residual within the system. Furthermore, given the legal standing of the Statements/EHCPs, parents/carers of children and young people with high-level SEND have the law on their side when holding schools and LAs to account. In other words, there are external pressures that uphold the status quo in terms of providing TA support. However, easily auditable quantifications of support can have relatively little pedagogical value, and this can be pursued and enforced at the expense of ensuring high quality teacher-led teaching (Webster, 2014).

Secondly, while the currency of hours attends to the quantification of provision, in order to understand the specification of provision, it was necessary to obtain a sense of the teaching and support provided by teachers and TAs. On the basis of our analysis of 49 pupil-level case study reports, it was difficult to define the pedagogical approaches teachers used to meet the learning needs of pupils with Statements/EHCPs. Implicit and ambiguous notions of 'teaching' in relation to SEND - and how that is distinct from the equally fuzzy notion of 'support' - plus the absence of a nuanced take on differentiation (see below), suggest there is a gap in teachers' knowledge when it comes to SEND and pedagogy as it relates to SEND. The infrequent and vague mentions of instructional practices may be attributable to that fact that teachers are not adept at accurately reporting and describing what they do (Nuthall, 2007); teachers struggle to make the implicit explicit. Another explanation could be that approaches to teaching for pupils with learning difficulties may not be as materially different and distinguishable from approaches that work for all learners, as we perhaps intuitively believe (Davis and Florian, 2004).

Thirdly, consistent with the earlier MAST study (Webster and Blatchford, 2015), we found ambiguity and open-endedness in conceptualisations and operationalisations of differentiation. Most noteworthy was the way setting and (as we put it) streaming were often referred to as differentiation strategies. The justification for so-called 'ability' grouping is surprisingly undeveloped, but is presumably built on the assumption that teaching becomes more effective or efficient with a narrower range of attainment in a class. Yet, while 
homogeneous grouping has been shown to have some benefit for higher-attaining pupils, it can be detrimental to the learning of average- and lower-attaining pupils (Francis et al., 2017; Kutnick et al., 2005), and can have a corrosive effect on the confidence and self-concept for those in the 'bottom' group (Taylor et al., 2016).

In summary, we were unable to find evidence of an effective and theoretically-grounded pedagogy for pupils with SEND in the instructional approaches used by either teachers or TAs. Drawing this together with the main findings above, it is difficult not to question the quality, appropriateness and effectiveness of educational provision on offer to pupils with SEND, compared to that received by their peers. While it is true we did not routinely interview headteachers as part of the SENSE study, in the evidence from interviews with SENCOs, teachers and TAs, there appeared to be an absence of strong leadership with respect to SEND.

\section{Implications and recommendations}

Wedell (2005) in the UK and Giangreco and colleagues $(2005 ; 2007)$ in the USA argue that the increased number, and sustained use, of TAs has staved off debates about how we effectively educate pupils with SEND in mainstream settings. In England, after almost two decades of year-on-year increases, the proportion of TAs in secondary schools has started to decline; down 8\%, from a 2013 high of 54,400 (DfE, 2017b).

While the trend relating to TA numbers appears to be a downward one, official projections of the pupil population illustrate a trend in the opposite direction. It is anticipated that the number of children and young people with needs complex enough to require an EHCP will grow by around 20,000 between 2017 and 2026; about 15\% of the current population (DfE, 2017c). Another trend revealed by government data show that the number of special schools in England is also in decline. Over the last 20 years, the number of special schools has reduced by 16\%: from 1,239 in 1997 to 1,037 in 2017 (DfE, 2017d). This capacity would need to be reinstated within eight years in order to accommodate the projected increase in pupil numbers. As this seems highly improbable, it is almost inevitable that mainstream schools will be required to respond to this challenge by adopting more inclusive practices.

The contribution of the SENSE study is, therefore, timely and important. Obtaining a detailed understanding of what pupils with high-level SEND experience, and how schools organise to deliver provision to meet their needs, is essential to making effective judgments about which provisions work best. The summation of the organisational structures and operational contexts within which pupils with high-level SEND are taught in mainstream settings, as revealed through the present study, lead us to a profound and troubling thought: given the prevailing trends, to what extent does the widespread use of TAs to facilitate the inclusion and teaching of pupils with SEND compensate or cover for failures elsewhere in system? Put another way, if TAs were removed from schools tomorrow, how effectively would schools manage without them - and for how long?

The systemic and long-standing failure to develop alternative approaches, such as more appropriate teaching, is likely to be exposed if the number of TAs and special school places fall as the proportion of pupils with SEND increases. The challenge facing mainstream schools (in England, at least) is how best to respond. So, what could they do? 
Firstly, secondary schools could take the bold step of mixed attainment teaching, for at least some subjects and contexts. Compared with classes organised on the basis of 'ability', mixed attainment teaching has greater potential to improve outcomes for all pupils (Taylor et al., 2016). At the least, schools should adopt grouping strategies that mitigate the more harmful effects of streaming or 'hard' setting (Francis et al., 2017). In lessons, teachers should ensure pupils with SEND are not routinely clustered together for group work, but have opportunities to interact, work with and learn from others.

Secondly, consistent with our work on the deployment of teaching assistants (Webster et al., 2016), the SENSE study findings provide more evidence for schools to be mindful of, and address, institutional arrangements and classroom practices that result in pupils with Statements/EHCPs having more time with TAs and less time with teachers (relative to other pupils). TAs should be part of a wider, more balanced and coherent, set of responses to meeting the needs of pupils with high-level SEND - not the default setting.

Thirdly, we require teachers to be more confident and competent in relation to SEND. They require not only input on types of SEND, but on effective and theoretically-grounded pedagogic approaches. Schools need to bring to light not only the practices of effective teaching for SEND, but the processes by which they were developed. Rather than looking for practices that will transfer wholesale into another setting, efforts to unpick the professional thinking, trialling and reflection underpinning effective strategies and techniques have the potential to demystify pedagogy and empower schools to develop inclusive approaches and identities.

Finally, governing bodies and boards of trustees, together with leadership teams, could institute career progression systems for teachers and leaders throughout the organisation that are contingent on evidencing practice that has a demonstrable impact on outcomes for pupils with SEND. Hard-wiring excellence for SEND into performance management and promotion means schools would be incentivised to provide quality CPD to support staff development and practice.

In terms of future research directions, the SENSE study reveals a need to address the lack of quality empirical evidence on effective pedagogic practices for pupils with SEND in mainstream settings (Rix et al., 2009). This is an equally clear need for this research effort to move beyond desk-based literature reviews, and into schools and classrooms, with researchers collaborating with teachers on the task of drawing out their conscious and unconscious pedagogic competences. Our study found strong evidence that pupils with SEND in mainstream schools spend almost all their time in low attainment sets. A second direction for future research would, therefore, be a closer exploration of the educational experiences within these sets, and what role they play in pupils' longer term educational progress.

\section{Acknowledgements}

We would like to thank the fieldwork team and the smaller team who painstakingly prepared 550 pages of case study material for analysis. Next, we thank the school staff who helped secure informed consent from families. We thank the expert group of professionals, practitioners and researchers with whom we shared our emerging findings and reflections. The SENSE study was funded by a grant from the Nuffield Foundation. 


\section{Notes}

${ }^{1}$ During the period this study took place (2015 to 2017), all Statements were in the process of being converted into EHCPs.

${ }^{2}$ Local authorities are a form of public administration devolved from central government.

3 Pupils in the MAST study had SEND related to moderate learning difficulties or behavioural, emotional or social difficulties. Following the SEND reforms of 2014, the latter category did not exist at the time of the SENSE study, and the former was absorbed into a broader category of cognition and learning. Pupils whose needs fall within the category of cognition and learning have greater difficulty than their peers in acquiring basic literacy and numeracy skills, and in understanding concepts. They may also have associated speech and language delay, lower self-esteem, lower levels of concentration and under-developed social skills, compared to pupils without SEND.

\section{References}

Blatchford, P., Russell, A. and Webster, R. (2012) Reassessing the Impact of Teaching Assistants: How Research Challenges Practice and Policy, Oxon: Routledge.

Cohen, L. and Manion, L. (1994) Research methods in education (4th edn), London, Routledge

Davis, P. and Florian, L. (2004) Teaching strategies and approaches for pupils with special educational needs: A scoping study. Research Report 516, London: Dept. for Education and Skills.

Dept. for Education (2017a) Statements of SEN and EHC plans: England, 2017. https://www.gov.uk/government/statistics/statements-of-sen-and-ehc-plans-england-2017. Accessed 25.05.17.

Dept. for Education (2017b) School Workforce in England: November 2016, London: DfE. https://www.gov.uk/government/statistics/school-workforce-in-england-november-2016. Accessed 22.06.17.

Dept. for Education (2017c) National pupil projections: July 2017. https://www.gov.uk/government/statistics/national-pupil-projections-july-2017. Accessed 11.12.17.

Dept. for Education (2017d) Special educational needs in England: January 2017. https://www.gov.uk/government/uploads/system/uploads/attachment data/file/633031/S FR37 2017 Main Text.pdf. Accessed 11.12.17.

Dept. for Education (2016a) Special Educational Needs: An Analysis and Summary of Data Sources, London, DfE. 
Dept. for Education (2016b) Statements of SEN and EHC plans: England, 2016. SFR17/2016, London: DfE. https://www.gov.uk/government/statistics/statements-of-sen-and-ehc-plansengland-2016. Accessed 17.04.17.

Dept. for Education (2016c) Special educational needs in England: January 2016. https://www.gov.uk/government/statistics/special-educational-needs-in-england-january2016. Accessed 17.04.17.

Dept. for Education (2016d) Schools, pupils and their characteristics: January 2016. SFR 20/2016, London: DfE.

https://www.gov.uk/government/uploads/system/uploads/attachment data/file/552342/S FR20 2016 Main Text.pdf. Accessed 17.04.17.

Francis, B., Archer, L., Hodgen, J., Pepper, D., Taylor, B. and Travers, M-C. (2017) Exploring the relative lack of impact of research on 'ability grouping' in England: A discourse analytic account, Cambridge Journal of Education, 47(1), pp, 1-17.

Giangreco, M.F., and Doyle. M.B. (2007) 'Teaching assistants in inclusive schools', in The Sage Handbook of Special Education, ed. L. Florian, pp. 429-439, London: Sage.

Giangreco, M.F., Yuan, S., McKenzie, B., Cameron, P. and Fialka, J. (2005) Be careful what you wish for...': Five reasons to be concerned about the assignment of individual paraprofessionals, Teaching Exceptional Children, 37(5), pp. 28-34.

Klassen, R. (2001) 'After the statement': reading progress made by secondary students with specific literacy difficulty provision, Educational Psychology in Practice, 17(2), pp. 121-133.

Kutnick, P., Sebba, J., Blatchford, P., Galton, M., Thorpe, J., MacIntyre, H., and Berdondini, L. (2005) The Effects of Pupil Grouping: Literature Review. Research Report 688, London: Dept. for Education and Skills.

Masdeu Navarro, F. (2015) Learning support staff: A literature review. OECD Education Working Papers, No. 125. http://dx.doi.org/10.1787/5jrnzm39w45l-en. Accessed 11.12.17.

Nuthall, G. (2007) The Hidden Lives of Learners, Wellington: NZCER Press.

Nye, P. (2017) Who's left: The main findings. Education Datalab.

http://educationdatalab.org.uk/2017/01/whos-left-the-main-findings/. Accessed 18.04.17.

O’Brien, J. (2016) Don't Send Him in Tomorrow, Carmarthen: Independent Thinking Press.

Ofsted (2016) The Annual Report of Her Majesty's Chief Inspector of Education, Children's Services and Skills 2015/16. London: Ofsted. https://www.gov.uk/government/uploads/system/uploads/attachment data/file/574186/0 fsted annual report education and skills 201516 web-ready.pdf. Accessed 17.04.17

Radford, J., Blatchford, P. and Webster, R. (2011) Opening up and closing down: Comparing teacher and TA talk in mathematics lessons, Learning and Instruction, 21(5) pp. 625-635. 
Rix, J., Hall, K., Nind, M., Sheehy, K. and Wearmouth, J. (2009) What pedagogical approaches can effectively include children with special educational needs in mainstream classrooms? A systematic literature review, Support for Learning, 24(2) pp. 86-94.

Rubie-Davies, C., Blatchford, P., Webster, R., Koutsoubou, M. and Bassett, P. (2010) Enhancing learning?: A comparison of teacher and teaching assistant interactions with pupils, School Effectiveness and School Improvement, 21(4) pp. 429-449.

Sikes, P., Lawson, H. and Parker, M. (2007) Voices on: Teachers and teaching assistants talk about inclusion, International Journal of Inclusive Education, 11(3), pp. 355-370.

Taylor, B., Francis, B., Archer, L., Hodgen, J., Pepper, D., Tereshchenko A. and Travers, M-C. (2016) Factors deterring schools from mixed attainment teaching practice, Pedagogy, Culture and Society, DOI: 10.1080/14681366.2016.1256908.

Walker, R. (1993) The conduct of educational case studies: Ethics, theory and procedures, in: M. Hammersley (Ed) Controversies in classroom research, (2nd edn), Buckingham, Open University Press, pp163-195.

Webster, R. (2014) 2014 Code of Practice: How research evidence on the role and impact of teaching assistants can inform professional practice, Educational Psychology and Practice, 30(3), pp. 232-237.

Webster, R. and Blatchford, P. (2017) The Special Educational Needs in Secondary Education (SENSE) study Final Report. A study of the teaching and support experienced by pupils with Statements and Education, Health and Care Plans in mainstream and special schools. http://maximisingtas.co.uk/assets/content/sense-final-report.pdf. Accessed 01.07.17.

Webster, R. and Blatchford, P. (2015) Worlds apart? The nature and quality of the educational experiences of pupils with a statement for special educational needs in mainstream primary schools, British Educational Research Journal, 41(2), pp. 324-342.

Webster, R. and Blatchford, P. (2013) The educational experiences of pupils with a statement for special educational needs in mainstream primary schools. Results from a systematic observation study, European Journal of Special Needs Education, 28(4), pp. 463-479.

Webster, R., Blatchford, P., Bassett, P., Brown, P., Martin, C. and Russell, A. (2010) Double standards and first principles: Framing teaching assistant support for pupils with special educational needs, European Journal of Special Needs Education, 25(4) pp. 319-336.

Webster, R., Russell, A. and Blatchford, P. (2016) Maximising the Impact of Teaching Assistants: Guidance for school leaders and teachers. Second edition, Oxon: Routledge.

Wedell, K. (2005) Dilemmas in the quest for inclusion, British Journal of Special Education, 32(1), pp. 3-11. 